\title{
ОЦЕНКА УСТОЙЧИВОСТИ ФИНАНСОВОЙ СИСТЕМЫ РЕГИОНА: ТЕОРИЯ И МЕТОДОЛОГИЯ
}

\author{
(c) 2021 Гончарук Ольга Васильевна \\ доктор экономических наук, профессор \\ СПб филиал Финансового университета при Правительстве РФ, Россия, Санкт-Петербург \\ E-mail: OlVGoncharuk@fa.ru

\section{(c) 2021 Путихин Юрий Евгеньевич} \\ кандидат экономических наук, профессор, Кафедра экономики и финансов \\ СПб филиал Финансового университета при Правительстве РФ, Россия, Санкт-Петербург
}

В статье с позиций общего методологического анализа понятия «устойчивость» предложено авторское определение «устойчивость финансовой системы региона». В качестве основополагающего для целей анализа устойчивости финансовой системы региона выбран подход, в рамках которого финансовая система региона рассматривается как совокупность взаимодействующих и взаимосвязанных между собой секторов: сектор государственных и муниципальных финансов, финансовый сектор региона, региональный сектор корпоративных и личных финансов. Рассмотрены подходы к формированию совокупности частных и интегрального показателей оценки устойчивости региональных финансовых систем и сформулирована авторская концепция".

Ключевые слова: устойчивость, финансовая система региона, устойчивость финансовой системы региона, показатели устойчивости финансовой системы региона и ее секторов.

Введение. Понятие «устойчивость» широко используется не только в технических, но и в гуманитарных и экономических науках, что свидетельствует о практической значимости понятия для изучения свойств рассматриваемых систем с целью повышения эффективности управления ими.

Что касается материальных систем, то в этом случае под устойчивостью понимают как сохранение относительных параметров движения относительно траекторий движения других систем (объектов) и утверждают, что движение системы устойчиво, если при малых отклонениях начальных параметров ее движения траектория мало отличается.

Следовательно, для системы определяются целевые показатели и система должна сохранять их под воздействием определенной совокупности внешних и внутренних факторов. Для систем социально-экономического характера, к которым относится финансовая система региона, движение заключается в повседневном функционировании, при этом для контроля эффективности управления ее устойчивостью рассчитываются основные показатели в динамике, а также прогнозные показатели, как на уровне отдельных подсистем/секторов финансовой системы, так и отдельных субъектов экономики, которые впоследствии сравниваются с реально полученными показателями.

Целевые ориентиры могут иметь как качественное, так и количественное описание, и по своей сути являются вероятностными, поскольку их достижение обусловлено множеством факторов, максимально учесть которые на этапе планирования / прогнозирования не представляется возможным и которые, поэтому, необходимо отслеживать для своевременного принятия мер по корректировке функционирования секторов/институтов финансовой системы региона.

Региональная финансовая система и ее устойчивость. Исследование вопросов, касающихся обеспечения устойчивости финансовой системы региона, включает в себя несколько аспектов. Во-первых, определение понятия «финансовая система региона», которое позволяет определить особенности объекта, устойчивость которого оценивается. Во-вторых, раскрытие понятия «устойчивость финансовой системы региона». В-третьих, выбор показателей, которые позволяют оценивать уровень устойчивости финансовой системы региона. В-четвертых, обо-

\footnotetext{
* Статья подготовлена в рамках выполнения научно-исследовательской работы «Обеспечение устойчивости финансовой системы региона: механизм, инструменты, показатели оценки» по государственному заданию в 2021 году
} 
снование границ отклонений текущих показателей от нормативных/прогнозных для принятия управленческих воздействий с целью нормализации текущего состояния финансовой системы.

Анализ подходов к определению понятия «финансовая система региона», изложенный в статьях Духовенко В.С. [13], Миленкова А.С. [23], Зотовой А.И. и Кириченко М.В. [16], Головановой Л.А., Крыловой А.И. и Новоселовой А. В. [12,] Завьяловой Д.А. [14] и др., показал целесообразность авторского определения: под финансовой системой региона мы понимаем совокупность финансовых институтов и субъектов экономики, осуществляющих на территории конкретного региона свою деятельность в соответствии с финансовым законодательством, целевыми установками и экономическими интересами, и отношений между ними в процессе формирования, распределения и использования финансовых ресурсов.

В качестве финансовых институтов выступают бюджеты (субъекта федерации, консолидированный, государственных и региональных фондов), институты финансового сектора (кредитные организации, страховые компании, микрофинансовые организации, негосударственные пенсионные фонды, паевые фонды и др.). Субъекты экономики - юридические и физические лица и индивидуальные предприниматели являются активными участниками финансовых отношений, при этом роль физических лиц существенно выросла за последнее время, как за счет развития индивидуального инвестирования, так и за счет цифровизации финансово-кредитных операций.

При том, что существуют различные подходы к структурированию финансовых систем: совокупность отдельных финансовых институтов [25], совокупность субъектов экономики, связанных финансовыми отношениями [27], совокупность кредитно-банковской, бюджетно-налоговой, платежной, валютной и др. подсистем [29], для анализа устойчивости финансовой системы региона будем рассматривать ее как совокупность секторов:

- сектора государственных и муниципальных финансов, представленного совокупностью бюджетов,

- финансового сектора, представленного банковским сектором, страховым сектором, сектором профессиональных участников рынка ценных бумаг, сектором инфраструктурных организаций, сектором субъектов рынка коллективных инвестиций, сектором паевых инвестиционных фондов, сектором субъектов микрофинансирования;
- сектора корпоративных финансов, представленного финансами юридических лиц;

- сектора личных финансов, представленного финансами физических лиц/домохозяйств и индивидуальных предпринимателей.

Такой подход позволяет оценивать устойчивость финансовой системы региона в целом, каждого сектора отдельно и вклад каждого сектора в обеспечение общей устойчивости региональной финансовой системы.

Понятие «устойчивость финансовой системы региона» в исследованиях трактуется по-разному. Так, ШимширтН.Д., трактует устойчивость финансовой системы региона как «способность территории рассчитываться по своим обязательствам, а также состояние экономики, при котором обеспечиваются условия для расширенного воспроизводства» [28, с. 172]; Миленков А.В. определяет устойчивость региональной финансовой системы как ее «способность выполнять свои функции в изменяющихся условиях» [23, с. 115]; Зотова А.И. и Кириченко М.В. предлагают рассматривать устойчивость финансовой системы региона как «способность региональной финансовой системы выполнять свои социально-экономические функции в условиях возмущающих воздействий внешних и внутренних рисков изменяющейся финансовоэкономической среды» [16, с. 76]; Алтуфьевой Т.А. понимает под финансовой устойчивостью региона «сбалансированность и пропорциональность роста финансовых ресурсов государства, бизнеса и населения в регионе, которые позволяют обеспечить выполнение полномочий региональных органов власти по повышению уровня жизни населения как в текущей, так и долгосрочной перспективе [4, с. 45].

В этих определениях отражаются следующие критерии устойчивости финансовой системы: a) функциональная стабильность финансовой системы; б) учет внешних факторов; в) прирост совокупного финансового потенциала региональной экономики институтов и субъектов экономики. Вместе с тем, возможны изменения не только внешней среды, но и внутренней среды региональной финансовой системы в части изменения пропорций между ее секторам, что также должно быть отражено в понятии устойчивости финансовой системы региона. Отдельный вопрос, заслуживающий обсуждения, это вопрос о степени влияния внешних факторов на устойчивость региональной финансовой системы. Очевидно, что кризисы могут быть не только глобальные и 
макроэкономические, которые существенно влияют на показатели ВРП, финансовые результаты корпоративного сектора и уровня жизни населения, но и региональные в результате различных форс-мажорных обстоятельств (ошибки в региональном финансовом планировании, банкротство или смена налоговой юрисдикции крупными предприятиями, технологические сдвиги и др.). Таким образом, в случае глобальных и особенно макроэкономических кризисов устойчивость финансовой системы региона может рассматриваться как случайное явление, поскольку в этом случае государством предпринимаются дополнительные меры для повышения устойчивости бюджетной системы и секторов экономики, которые существенно затронуты кризисом. Поэтому устойчивость региональной финансовой системы должна быть обусловлена в первую очередь стабильными и прогнозируемыми изменениями внешней среды и иметь ресурсы для преодоления внутрирегиональных кризисных ситуаций. Таким образом, проведенный анализ подходов к исследованию вопросов обеспечения устойчивости финансовой системы региона позволили дать следующее авторское определение: устойчивость финансовой системы региона - это ее способность сохранять параметры функционирования в условиях относительно стабильного состояния внешней среды и внутренних изменений как отдельных секторов, так и пропорций между нuмu.

Отметим, что как показала эпидемия Ковида-19, каждый сектор по-разному реагирует на форс-мажорные внешние факторы, что в определенной степени отражено в Таблице 1, где представлены обобщающие показатели по сектору

Таблица 1. Финансовые показатели по основным секторам финансовой системы РФ, 2016-2020 гг.

\begin{tabular}{|c|c|c|c|c|c|}
\hline & 2016 & 2017 & 2018 & 2019 & 2020 \\
\hline ВВП, млрд. руб. & 85616,1 & 91843,2 & 103861,7 & 109193,2 & 106967,5 \\
\hline Темпы инфляции,\% & 5,4 & 2,5 & 4,3 & 3,0 & 4,9 \\
\hline \multicolumn{6}{|l|}{ Бюджеты РФ } \\
\hline Консолидированный бюджет РФ & 28181,5 & 30640,0 & 37320,3 & 39497,6 & 37856,7 \\
\hline в\% к ВВП & 32,7 & 33,3 & 35,7 & 36,2 & 35,4 \\
\hline Консолидированные бюджеты субъектов РФ & 9921 & 10755 & 12389 & 13572 & 14901 \\
\hline в\% к ВВП & 11,6 & 11,7 & 11,9 & 12,4 & 13,9 \\
\hline Федеральный бюджет & 13460,0 & 15088,9 & 19454,4 & 20188,8 & 18722,2 \\
\hline в\% к ВВП & 15,6 & 16,4 & 18,6 & 18,5 & 17,5 \\
\hline \multicolumn{6}{|l|}{ Финансовый сектор } \\
\hline Активы финансового сектора, трлн. руб.*** & 88,0 & 94,8 & 105,5 & 115,3 & 126,3 \\
\hline В\% к ВВП* & 102,8 & 103,2 & 101,6 & 105,6 & 118,5 \\
\hline \multicolumn{6}{|l|}{ В том числе } \\
\hline \multicolumn{6}{|l|}{ Банковский сектор } \\
\hline Активы, млрд. руб.**** & 80063 & 85172 & 94084 & 96581 & 103842 \\
\hline $\mathrm{B} \% \mathrm{k} \mathrm{ВB \Pi}{ }^{* * * *}$ & 92,9 & 92,6 & 89,9 & 87,8 & 97,1 \\
\hline В\% к активам финансового сектора* & $87,5^{*}$ & 85,8 & 84,9 & 82,3 & 82,0 \\
\hline Прибыль, млрд. руб. & 930 & 790 & 1345 & 1700 & 1600 \\
\hline \multicolumn{6}{|l|}{ Страховой сектор } \\
\hline Активы, млрд. руб. & 1871,4 & 2429,7 & 2918,9 & 3334,7 & 3811,0 \\
\hline в\% к ВВП & 2,18 & 2,64 & 2,82 & 3,2 & 3,6 \\
\hline Прибыль, млрд. руб. & 81,9 & 84,0 & 164,9 & 207,4 & 201,0 \\
\hline \multicolumn{6}{|l|}{ Корпоративный нефинансовый сектор } \\
\hline Доходы (оборот), млрд. руб. & 146376,8 & 158778,0 & 191813,3 & 201315,5 & $186403,21)$ \\
\hline$\%$ к ВВП & 171,0 & 172,9 & 184,7 & 184,4 & 174,3 \\
\hline Прибыль, млрд. руб. & 15823 & 14079 & 18332,719 & 17696,266 & 17758,3 \\
\hline \multicolumn{6}{|l|}{ Сектор личных финансов } \\
\hline Доходы населения & 54117,7 & 55466,6 & 58458,7 & 62080,1 & 62700,8 \\
\hline$\%$ к ВВП & 63,2 & 60,4 & 56,2 & 56,9 & 58,6 \\
\hline
\end{tabular}

Составлено по: $[6,7,8,26]$. 
государственных муниципальных финансов, финансовому сектору, сектору корпоративных финансов и сектору личных финансов.

Как следует из данных Таблицы 1 , по итогам 2020 года наблюдалась разнонаправленная динамика: при снижении размера ВВП, консолидированного бюджета РФ, федерального бюджета, доходов корпоративного сектора, выросли объемы консолидированных бюджетов субъектов федерации, активы финансового сектора, в том числе и банковского, и страхового, доходы населения страны. При этом 2020 год следует рассматривать как кризисный, что определило использование государством специальных финансовых механизмов для поддержки региональных финансовых систем, корпоративного сектора и сектора личных финансов.

Показатели устойчивости финансовой си- стемы региона. Эффективность развития финансовых систем, в том числе региональных, оценивается через комплекс показателей. При этом существуют различные подходы к определению их состава. Так, в 2007 году Международный Валютный Фонд опубликовал документ «Показатели финансовой устойчивости», в котором приведены показатели по отдельным институциональным единицам, под которыми в документе понимаются «домашние хозяйства, корпорации или государственные учреждения, которые могут от своего имени владеть активами, принимать обязательства, осуществлять экономическую деятельность и проводить операции с другими секторами» [25, с. 11], а также указаны показатели, которые, по мнению разработчиков, характеризуют финансовую устойчивость отдельных институциональных единиц (Таблица 2).

Таблица 2. Показатели финансовой устойчивости [25, с. 194].

\begin{tabular}{|c|c|}
\hline $\begin{array}{c}\text { Институциональные } \\
\text { единицы }\end{array}$ & Показатели \\
\hline $\begin{array}{l}\text { Депозитные организации } \\
\text { (кредитные организации) }\end{array}$ & $\begin{array}{l}\text { Отношение нормативного капитала к активам, взвешенным по риску } \\
\text { Отношение нормативного капитала первого уровня к активам, взвешенным по } \\
\text { риску } \\
\text { Отношение необслуживаемых кредитов за вычетом созданных резервов к капи- } \\
\text { талу } \\
\text { Отношение необслуживаемых кредитов к совокупным валовым кредитам и } \\
\text { займам } \\
\text { Отношение распределения кредитов и займов по секторам к совокупным кре- } \\
\text { дитам и займам } \\
\text { Норма прибыли на активы } \\
\text { Норма прибыли на собственный капитал } \\
\text { Отношение процентной маржи к валовому доходу } \\
\text { Отношение непроцентных расходов к валовому доходу } \\
\text { Отношение ликвидных активов к совокупным активам (коэффициент ликвид- } \\
\text { ных активов) } \\
\text { Отношение ликвидных активов к краткосрочным обязательствам } \\
\text { Отношение чистой открытой валютной позиции к капиталу }\end{array}$ \\
\hline $\begin{array}{l}\text { Некредитные финансовые } \\
\text { корпорации }\end{array}$ & $\begin{array}{l}\text { Отношение активов к совокупным активам финансовой системы } \\
\text { Отношение активов других финансовых корпораций к ВВП }\end{array}$ \\
\hline $\begin{array}{l}\text { Нефинансовые корпора- } \\
\text { тиции }\end{array}$ & $\begin{array}{l}\text { Отношение собственного долга к собственному капиталу } \\
\text { Норма прибыли на собственный капитал } \\
\text { Отношение прибыли (до уплаты процентов и налогов) } \\
\text { к расходам по процентам и основной сумме } \\
\text { Отношение чистой открытой валютной позиции } \\
\text { к собственному капиталу } \\
\text { Число заявлений с просьбой защиты от кредиторов } \\
\text { Отношение Пднп к объему продаж }\end{array}$ \\
\hline Домашние хозяйства & $\begin{array}{l}\text { Отношение долга домашних хозяйств к ВВП } \\
\text { Отношение расходов домашних хозяйств на обслуживание долга и на выплату } \\
\text { основной суммы к доходу }\end{array}$ \\
\hline Рыночная ликвидность & $\begin{array}{l}\text { Средний спред между курсами покупателей и продавцов на рынке ценных } \\
\text { бумаг } \\
\text { Коэффициент среднедневной оборачиваемости на рынке ценных бумаг } \\
\text { Цены на недвижимость }\end{array}$ \\
\hline Рынки недвижимости & $\begin{array}{l}\text { Отношение кредитов и займов на жилую недвижимость к совокупным креди- } \\
\text { там и займам } \\
\text { Отношение кредитов и займов на коммерческую недвижимость к совокупным } \\
\text { кредитам и займам }\end{array}$ \\
\hline
\end{tabular}


Как следует из данных, приведенных в Таблице 2, в документе МВФ отдельно не рассматриваются показатели, характеризующие сектор государственных и муниципальных финансов; по кредитным организациям, помимо приведенных 12 базовых показателей, рекомендуются также 14 дополнительных показателей; показатели, которые рекомендуются МВФ, могут рассматриваться как плановые/прогнозные. Достаточность или избыточность показателей по отдельным институциональным единицам определяется эмпирическим путем.

Для российской экономики сектор государственных и муниципальных финансов является существенно значимым, поскольку через бюджетную систему перераспределяется более 35\% ВВП (см. Таблицу 1). Поэтому региональным финансам отводится важная роль в обеспечении финансовой стабильности российской экономики. Так, Министерством финансов России с 2011 года осуществляется оценка качества управления региональными финансами [3] по следующим направлениям:

1) бюджетное планирование;

2) исполнение бюджета;

3) управление государственным долгом;

4) финансовые взаимоотношения с муниципальными образованиями, в том числе по следующим мероприятиям: эффективность межбюджетных отношений на региональном уровне; взаимодействие органа государственной власти субъекта Российской Федерации с муниципальными образованиями по обеспечению выполнения ограничений по организации бюджетного процесса на региональном уровне; деятельность органов государственной власти субъектов Российской Федерации по совершенствованию организации местного самоуправления и развитию инициативности граждан;

5) управление государственной собственностью и оказание государственных услуг;

6) прозрачность бюджетного процесса;

7) индикаторы, характеризующие выполнение указов Президента Российской Федерации, включая: выполнение указов Президента Российской Федерации от 7 мая 2012 г.; выполнение Указа Президента Российской Федерации от 7 мая 2018 г. N 204 «О национальных целях и стратегических задачах развития Российской Федерации на период до 2024 года».

При этом оценке долговой устойчивости регионов придается особое значение. Так, в соответствии с Бюджетным Кодексом РФ каждый субъект федерации обязан разрабатывать документ «Основные направления государственной долговой политики», в котором должны быть отражены [1, ст. 107.1, п. 13]: 1) итоги реализации долговой политики; 2) основные факторы, определяющие характер и направления долговой политики; 3) цели и задачи долговой политики; 4) инструменты реализации долговой политики; 5) анализ рисков для бюджета, возникающих в процессе управления государственным долгом субъекта Российской Федерации (муниципальным долгом); 6) иные положения в соответствии с правовыми актами, регулирующими бюджетные отношения. Министерством финансов Российской Федерации в соответствии со статьей 107.1 БК РФ в сентябре 2020 года была осуществлена по итогам 2019 г. оценка долговой устойчивости субъектов Российской Федерации в порядке, установленном постановлением Правительства Российской Федерации «Об утверждении Правил проведения оценки долговой устойчивости» от 04.03.2020 № 227 [2]. Кроме того, Бюджетным Кодексом РФ с 1 июля 2021 года расширен состав показателей оценки долговой устойчивости регионов [1, ст. 107.1, п. 5], что определяет более жесткие требования к управлению региональными финансами.

Отметим, что бюджет субъекта федерации является важным институтом, обеспечивающим устойчивость финансовой системы региона, но вместе с тем, на общую устойчивость влияет состояние финансового сектора, сектора корпоративных финансов, сектора личных финансов.

Финансовый сектор, который находится в зоне ответственности Банка России, включает совокупность секторов: банковский, страховой, профессиональных участников рынка ценных бумаг, инфраструктурных организаций, субъектов рынка коллективных инвестиций; паевых инвестиционных фондов; субъектов микрофинансирования в целом характеризуется неравномерностью развития. При этом ведущим сектором является банковский сектор, на долю которого приходится более $82 \%$ активов всего финансового сектора [8]. Банк России в «Обзоре финансовой стабильности» оценивает уровень устойчивость банковского сектора по итогам 2020 года как высокий на основании следующих (базовых) показателей [9, с .5]:

- рост активов в сопоставимых ценах составил 2,5\%;

- прибыль банковского сектора составила порядка 1,6 трлн. руб. 
- рентабельность активов по состоянию на 01.04.2021 года составила 1,6\%, а рентабельность балансового капитала - 15,8\%;

- совокупные потери банков в перспективе оцениваются в 1,4 трлн. руб., а накопленный запас капитала составляет 6,0 трлн. руб.

Оценка устойчивости некредитных финансовых организаций (страховых компаний, негосударственных пенсионных фондов, брокерских организаций) осуществляется по следующим основным показателям: размер и качество активов, прибыль. При этом Банком России сделан вывод о том, что положение этих секторов по итогам 2020 года характеризуется как стабильное [9, с. 5].

Помимо базовых показателей Банком России определен широкий состав ключевых показателей для каждого вида финансового института, в том числе в региональном разрезе, что позволяет пофакторно анализировать состояние и тенденции их развития в динамике.

Для оценки финансового положения компаний Банк России рассматривает показатель долговой нагрузки по крупнейшим 90 российским публичным компаниям (Чистый долг /EBITDA), анализирует уровень кредитных рисков [9, с. 3, с. 21-25]. Что касается населения, то анализируются такие показатели как: совокупные доходы населения, банковские вклады, долговая нагрузка, риски розничного кредитования, сделан по итогам 2020 года вывод, что основной вклад в увеличение долговой нагрузки внесли необеспеченные потребительские кредиты [9, с. 4, 36-42].

Вместе с тем, общая оценка устойчивости региональных финансовых систем государственными органами не проводится. Этой проблеме посвящены исследования, в которых она рассмотрена в различных аспектах.

Буянова М.А. и Дятлов Д.А. предлагают совокупность показателей оценки рисков развития финансовой системы региона, которые отражают траекторию ее развития и, следовательно, по сути являются показателями для оценки устойчивости финансовой системы региона, а также характеризуют разработанную ими балльную оценку частных и совокупного рисков развития финансовой системы [10, с. 38-40].

Колесов А.С., рассматривая показатели оценки региональной финансовой политики, излагает подход, в котором рассчитываются показатели для оценки устойчивости бюджетного сектора через доходы, расходы и государственный долг [20, с. 40-41].
Любимцев К.И. и Галлямов Ф.Ф. полагают, что основной функцией финансовой системы региона является воспроизводственная и ее обобщающими показателями являются: объем и динамика ВРП и динамика регионального производственного капитала [21, с. 27].

Зотова А.И., Кириченко М.В., анализируя сущность, факторы и индикаторы устойчивости финансовой системы региона, выделяют критерии устойчивости финансовой системы региона (социально-экономический, бюджетноналоговый, инвестиционный, структурнофункциональный), по каждому из которых определяют совокупность показателей, раскрывающих, по мнению авторов, особенности каждого критерия [15, с. 81].

Печаткин В.В. предлагает для оценки финансовой устойчивости региона в качестве целевой функции - отношение доходов консолидированного бюджета на душу населения к величине прожиточного минимума в регионе, и совокупность показателей, характеризующих, по его мнению, состояние финансовой системы региона. В качестве интегрального показателя выбран отношение суммы по семи факторам (показателям) к среднероссийскому аналогичному фактору [24, с. 24].

Ахметов Р.Р. к показателям устойчивости финансовой системы региона относит: дефицит бюджета в процентах к ВРП, бюджетную нагрузку по обслуживанию долга, региональную ликвидность, под которой понимается размер кредиторской и дебиторской непросроченной задолженности к ВРП или объему промышленного производства, долю дефицита бюджета в доходах бюджета. В качестве интегрального показателя оценки финансового положения бюджетной системы региона предлагается показатель отношения собственных доходов бюджета к расходам, умноженное на индекс изменения размера кредиторской задолженности предприятий региона за период [5, с. 64].

Васильева А.Г. и Гафурова В.М. исследуют взаимосвязь устойчивости финансовой системы региона и показателей социальноэкономического благополучия региона (численность населения, реальные денежные доходы и расходы населения, ВРП, инвестиции в основной капитал и др.) методами пофакторного регрессионного анализа [11, с. 39-40].

Канашина А.И. для оценки финансовой безопасности региона предлагает совокупность показателей, характеризующих бюджетную без- 
опасность, налоговую безопасность, кредитнобанковскую безопасность, безопасность финансового рынка [18, с. 34-35].

Катков Н.С. и Севастьянов В.В. [19]., Алтуфьева Т.Ю. [4], Ибрагимов Р.Н. [17] используют обобщенные формулы для оценки финансовой устойчивости региона, которые различаются отдельными параметрами и индикаторами. Так, Катков Н.С. и Севастьянов В.В. обосновывают в качестве интегрального показателя оценки устойчивости финансовой системы региона трехфакторную модель, учитывающую долю собственных доходов бюджета субъекта федерации в его расходах, изменение кредиторской и дебиторской задолженности корпоративного сектора и доли убыточных предприятий в регионе, каждый из параметров взвешен через соответствующий индикатор [25, с. 34-35].

Алтуфьевой Т.Ю. предложен двухэтапный подход к оценке финансовой устойчивости территориальных систем: на первом этапе оценивается бюджетная устойчивость (устойчивость бюджетных доходов), на втором этапе оценивается сбалансированность доходов и расходов регионального бюджета, бизнеса и населения по модифицированной формуле, разработанной Катковым Н.С. и Севастьяновым В.В., учитывающей собственные доходы и расходы бюджета, состояние корпоративного сектора (задолжен- ность и убыточность), доходы и расходы населения, которые скорректированы индикаторами (коэффициентами значимости), определенных эмпирическим путем, и которые сравниваются с пороговыми значениями интегрального показателя) [4, с. 45-46].

Ибрагимов Р.Н. для оценки финансовой устойчивости региона использует показатели, характеризующие бюджетную устойчивость и устойчивость корпоративного сектора, добавляя в качестве дополнительного параметра изменение темпов инфляции [17, с. 79-80].

Предлагаемые модели отражая определенные параметры финансового состояния секторов региональной финансовой системы вместе с тем не учитывают роль финансового сектора в регионе, что определяет необходимость корректировки предложенных моделей.

При этом, как мы полагаем, параметры модели должны быть взаимоувязаны с частными показателями оценки устойчивости секторов региональной финансовой системы.

В итоге проведенный анализ позволил сформировать обобщенную совокупность показателей устойчивости секторов финансовой системы региона, которые могут быть дополнены относительными показателями, в зависимости от глубины и целей проводимых расчетов (Таблица 3).

\section{Таблица 3. Показатели устойчивости секторов финансовой системы региона}

\begin{tabular}{|l|l|}
\hline Сектора финансовой системы & \\
\hline $\begin{array}{l}\text { мектор государственных и } \\
\text { Фильных финансов }\end{array}$ & $\begin{array}{l}\text { Доходы консолидированного бюджета, бюджета субъекта федерации } \\
\text { Расходены консолидированного бюджета, субъекта федерации } \\
\text { Дефицит/профицит консолидированного бюджета, бюджета субъекта феде- } \\
\text { рации }\end{array}$ \\
\hline Банковский сектор & $\begin{array}{l}\text { Вклады физических лиц, юридических лиц в кредитные организации в реги- } \\
\text { оне } \\
\text { Кредиты, выданные юридическим лицам, физическим лицам кредитными } \\
\text { организациями в регионе } \\
\text { Кредитная задолженность юридических лиц, физических лиц } \\
\text { Просроченная кредитная задолженность юридических лиц, физических лиц }\end{array}$ \\
\hline Страховой сектор & $\begin{array}{l}\text { Страховые премии, собранные страховыми организациями в регионе } \\
\text { Страховые выплаты }\end{array}$ \\
\hline Другие сектора & $\begin{array}{l}\text { Оборот (выруча) } \\
\text { Прибыль/убытки } \\
\text { Расходы } \\
\text { нансов корпоративных фи- уплаченные корпоративным сектором региона } \\
\text { Кредиторская и дебиторская задолженность } \\
\text { Доля убыточных предприятий }\end{array}$ \\
\hline Сектор личных финансов & $\begin{array}{l}\text { Доходы населения региона } \\
\text { Потребительские расходы населения } \\
\text { Налоги, уплаченные населением }\end{array}$ \\
\hline
\end{tabular}


Предлагаемая совокупность показателей не является исчерпывающей, но используется для построения модели интегрального показателя устойчивости финансовой системы региона, который учитывает финансовое состояние всех секторов и имеет вид:

$k_{1}\left(\right.$ Дскб / Ркб) $+k_{2}((\Delta В ю л+\Delta В ф л) /(\Delta К З ю л+$ $\Delta$ КЗфл) + Встр / Cnp $)+k_{3}\left(\Pi p, \kappa-\mathrm{У}_{K}-\right.$ Нюл $\left.) / P_{\kappa}\right) x$

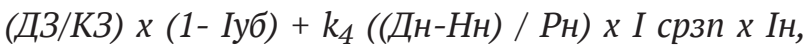
прм $\times(1-$ - Ікн, прм),

где

Дскб - собственные доходы консолидированного бюджета, расходы консолидированного бюджета;

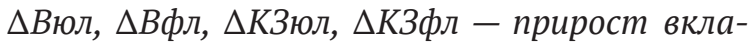
дов и кредитной задолженности юридических и физических лии соответственно;

Стр - страховые премии, собранные в регионе, Встр и страховые выплаты в регионе,

Пр,к - прибыль, полученная корпоративным сектором в регионе, Ук - убытки корпоративного сектора региона, Нк - налоги, уплаченные корпоративным сектором региона, $P_{\kappa}-$ расходы корпоративного сектора в регионе, Дз - дебиторская задолженность, КЗ - кредиторская задолженность, Іуб -доля убыточных предприятий в регионе;

Дн-доходы населения региона;

Нн - налоги, уплаченные населением региона;

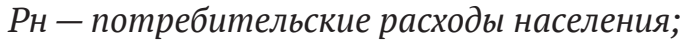

I срзп - изменение средней зарплаты в регионе;

Iн, прм - изменение прожиточного минимума в регионе;

Ікн, прм,- доля населения с доходами, ниже прожиточного минимума;

$k_{1}, k_{2}, k_{3}, k_{4}-$ коэффициенты, учитывающие вклад каждого сектора финансовой системы в ее интегральную устойчивость, $\Sigma k_{i}=1$.
Апробация предложенной модели интегральной оценки устойчивости финансовой системы регионов, проведенная на примере регионов СЗФО показала, что весовые коэффициенты $k_{i}$ определяются в зависимости от финансового потенциала региона, и уровня развития отдельных секторов финансовой системы.

\section{Заключение.}

Региональные финансовые системы являются важной составной частью национальной финансовой системы, обеспечивая социальноэкономическое развитие субъектов федерации. При этом, если вопросам совершенствования управления сектором государственных и муниципальных финансов уделяется большое внимание со стороны Министерства финансов России, а также обеспечения стабильности финансового сектора страны на макроэкономическом уровне и на уровне отдельных финансовых институтов - со стороны Банка России, то комплексная оценка устойчивости региональных финансовых систем осуществляется в инициативном и эпизодическом порядке учеными и практиками. При этом в целом существует относительное единство взглядов на отдельные частные показатели оценки финансового состояния бюджета, личных финансов и корпоративных финансов, вместе с тем, интегральные показатели, предлагаемые для оценки финансовой устойчивости территориальных систем нуждаются в обосновании и развитии. В статье изложен подход к формированию модели интегрального показателя устойчивости финансовой системы региона, который учитывает вклад финансового сектора в общую финансовую устойчивость, а также увязывает совокупность частных показателей в интегральный, расчет которого позволяет оценить устойчивость финансовой системы региона.

\section{Библиографический список}

1. Бюджетный Кодекс Российской Федерации. Ф3-145 от 31.07 .1998 (в ред. от 01.07.2021). - URL: // http://www. consultant.ru/document/cons_doc_LAW_19702

2. Об утверждении Правил проведения оценки долговой устойчивости. Постановление Правительства Российской Федерации от 04.03.2020 № 227. www.garant.ru/doc/maingarant.ru.

3. О порядке осуществления мониторинга и оценки качества управления региональными финансами. Приказ Министерства финансов Российской Федерации от 3 декабря 2010 года № 552 (с изм. и доп.). // www. garant.ru/doc/maingarant.ru

4. Алтуфьева Т.Ю. Финансовая устойчивость территориальных систем: методика оценки и результаты апробации // Экономика и управление: научно-практический журнал. - 2014. - № 4 (120). - С. 44-50. 
5. Ахметов P.P. Проблемы методики оценки финансовой системы региона // региональная экономика: теория и практика. $-2010 .-25$ (160). - С. 62-67.

6. Банк России. Годовые отчеты. 2016-2020 гг.- URL: https://cbr.ru

7. Банк России. Отчеты о развитии финансового сектора. 2016-2020 гг. - URL: https://cbr.ru.

8. Банк России. Обзор российского финансового сектора и финансовых инструментов. Аналитический материал. 2020.- M., 2021._- URL: https://cbr.ru/Collection/Collection/File/32168/overview_2020.pdf

9. Банк России. Обзор финансовой стабильности: Информационно аналитический материал. - 2021. - № 1.URL: https://cbr.ru/Collection/Collection/File/33327/OFS_21-1.pdf.

10. Буянова М.А. и Дятлов Д.А. Риски финансовой системы региона. // Финансы и кредит.- 2008. - № 37 (325).- C. 36-42.

11. Васильева А.Г., Гафурова В.М. Эффективность управления финансовой устойчивостью субъектов Российской Федерации и социально-экономическое благополучие // Российские регионы в фокусе перемен: сб. докл. ХІ Международной конференции. В 2-х тт.- Екатеринбург: Изд-во «ООО УМЦ УПИ», 2016.- С. 128 136.

12. Голованова Л.А., Крылова А. И., Новоселова А.В. Сущность финансовой системы региона // Ученые записки ТОГУ.-2016.- Том 7.- № 4.- С. 610-617.

13. Духовенко В.С. Финансовая система региона: принципы формирования и развития // Фундаментальные исследования. - 2014. - № 12 (часть 11).- С. 2388-2392.

14. Завьялова Д. А. Современные подходы к определению категории «региональная финансовая система // Финансы и кредит. - 2018.- Т. 24.№ 11.-С. 2568-2577.

15. Зотова А.И., Кириченко М.В. Устойчивость финансовой системы региона: сущность, факторы, индикаторы // Теория и практика общественного развития. 2017. - № 5.- С. 76-82.

16. Зотова А.И., Кириченко М.В. Финансовая система региона: структурно-функциональный аспект // Современная наука: актуальные проблемы теории и практики. - 2015. - № 11-12.- С. 82-86.

17. Ибрагимов P.Н. Методика интегральной оценки финансовой устойчивости региональной экономики на примере Алтайского края. // Экономическая наука современной России. - 2020. - № 3. - С. 77-90.

18. Канашина А.И. Разработка системы диагностики финансового состояния регионов // В центре экономики. - 2020.- № 1.-С. 34-39.

19. Катков Н.С., Севастьянов В.В. Оценка финансовой устойчивости региона на примере Республики Марий Эл // Вопросы современной науки и практики. - 2009. - № 1. - С. 39-46.

20. Колесов А.С. О показателях оценки региональной финансовой политики. // Финансы. - 2013. - № 12.- С. $40-47$.

21. Любимцев К.И., Галлямов Ф.Ф. Формирование новых свойств финансовой системы региона. Финансовая экономика. 2011. № 5-6. С. 23-29.

22. Миленков А.В. Методология институционального анализа устойчивости финансовой системы // МИР (Модернизация. Инновации. Развитие). - 2016, Т.7. - № 4.- С. 115-120.

23. Миленков А. В. Сущность, структура и функции финансовой системы региона // Вестник Воронежского института инженерных технологий. - 2015.- № 4.- С. 233-238.

24. Печаткин В.В. Финансовая устойчивость и конкурентоспособность региона: методологические и прикладные аспекты оценки // Финансовая аналитик: проблемы и решения. - 2013. - № 42 (180) - С. 19-27.

25. Показатели финансовой устойчивости. Руководство по составлению.- Вашингтон округ Колумбия, США: Международный Валютный Фонд, 2007. - 312 c. - URL: file:///C:/Users/User/Downloads/guide.pdf.

26. Росстат. Россия в цифрах: Крат. стат. сб. 2017-2020._ URL: https://rosstat.gov.ru.

27. Финансово-организационные механизмы в современных условиях: вопросы теории и практики: коллективная монография / под общ. ред. О.В. Гончарук.- СПб.: СПбГЭИУ, 2009.- 348 с.

28. Шимширт Н.Д. Анализ теоретических аспектов финансовой устойчивости регионов // Вестник Томского государственного университета. - 2011. - № 3 (175). - С. 172-178.

29. Эскиндаров М.А. Устойчивость финансовой системы России: индикаторы и критерии оценки // Вестник Финансового университета. - 2012.- № 2.- С. 8-18. 